\title{
What is the Role of Technology in Recruitment and Selection?
}

\author{
Ioannis Nikolaou $\mathbb{D}$ \\ Athens University of Economics and Business (Greece)
}

\begin{abstract}
We explore a number of new developments in the field of employee recruitment and selection with a focus on recent technological developments. We discuss examples of technological developments across the four stages of the recruitment and selection process. In the attraction stage we discuss how on-line/internet recruitment and especially social networking websites have changed dramatically the focus of attracting candidates effectively. In the next stage of screening, we discuss how cybervetting and applicant tracking systems offer opportunities but also threats for recruiters and candidates. In the third stage of employee selection, we focus especially on two new selection methods; the asynchronous/digital interview and gamification/games-based assessment, along with the critical role and impact applicant reactions have on the selection process. Finally, we briefly discuss the main technological developments in on-boarding and socialization, and we conclude with a few suggestions for future research in this field.
\end{abstract}

Received 5 November 2020; Revised 20 December 2020; Accepted 11 January 2021

Keywords: applicant reactions, employee recruitment, employee selection, technology

Employee recruitment, selection, and assessment has been for many years and still remains one of the most prominent and important areas of research and practice in both work/organizational psychology (Ryan \& Ployhart, 2014) and human resource management (Markoulli et al., 2017). Dealing traditionally with the successful attraction, assessment, selection and onboarding of employees in an organization, it has always been a critical and expensive operation in every organization.

More recently though, employee recruitment and selection has been heavily affected by the emergence of technology, influencing all different aspects of the recruitment and selection cycle (Woods et al., 2020). New and various forms of technological developments - and not only the use of the internet or the widely used Social Networking Websites - have appeared, making a strong impact on the way recruiters work and job seekers look for a job. This changing landscape of the field, due to technology, has attracted increased research interest, not only in the field of work/organizational

Correspondence concerning this article should be addressed to Ioannis Nikolaou. Athens University of Economics and Business. Department of Management Science and Technology. 10434 Athens (Greece).

E-mail: inikol@aueb.gr

Conflicts of Interest: None.

Funding Statement: This work was supported with funding by the Athens University of Economics \& Business Research Centre (EP-306901). psychology and human resources management but also in the fields of computer / data science and engineering (e.g., Montuschi et al., 2014; Obaid et al., 2020)

However, as mentioned by van Iddekinge et al. (2016) regarding the gap between research and practice in the use of social networking websites in recruitment and selection, research in the use of technology in recruitment and selection still lags behind its extensive use in practice. Although a number of studies have appeared recently on various technology-related issues and their interaction with recruitment and selection, we still need more research on this topic. Our aim in this brief article is to present some proposals that researchers may find useful while studying and researching in these fields, with a work and organizational psychology focus, across the four different phases of the recruitment lifecycle.

\section{Technology and Recruitment/Selection}

Recruitment and selection have probably benefited the most from the advent of technological solutions during the last few decades. The first studies exploring the role of e-hr appeared early in the 2000s (Karakanian, 2000;

How to cite this article:

Nikolaou, I. (2021). What is the role of technology in recruitment and selection? The Spanish Journal of Psychology, 24. e2. Doi:10.1017/SJP.2021.6 
Stanton \& Coovert, 2004) predicting the beneficial impact of technology, across the different HR functions. Back then, the focus was on topics such as the use of the intranet, e-learning, virtual teams, HR Information Systems, etc. Nevertheless, internet recruitment, employment / career websites and on-line psychological testing (Bartram, 2000; Lievens \& Harris, 2003) were also in the forefront of those first attempts to study and predict how technology will change the landscape of research and practice in recruitment and selection.

Today, two decades since these articles first appeared, things have progressed a lot; technology has made a tremendous progress across all different aspects of social and professional life. Especially, in recruitment and selection, technology has affected the whole recruitment and selection lifecycle. In the following sections we will describe a number of technological developments that have affected the four main stages of the recruitment and selection process: attraction; screening, selection and on-boarding.

\section{Technology in Attraction}

The first stage of the recruitment and selection process includes the attraction phase. Chapman and Mayers (2015) emphasize the crucial but often undermined role of attraction, as the "series of systems, processes and strategies designed to maximize the size and quality of the applicant pool" (p. 27). Attraction is not identical to recruitment, especially in todays' digital era. Recruitment is broader, including many different elements, important for the whole selection process, such as the different activities organizations undertake in order to identify a desirable group of candidates, attract them into their employee ranks, and retaining them at least for the short term (Taylor \& Collins, 2000, p. 306). Recruitment should also be aligned with the organizations' strategic objectives, therefore especially today, it should include all technology-related activities that influence the recruitment and selection cycle, such as employer branding, candidate experience, etc.

Internet-based, or on-line recruitment was one of the first technological developments in the field that has attracted increased attention both from researchers and practitioners (Bartram, 2000). Job boards/job sites offering employers the opportunity to advertise their job openings online to a wide audience were the first applications in on-line recruitment and are still used heavily nowadays, since they are often perceived (and probably they are) as highly effective from both recruiters and job applicants (Nikolaou, 2014). Similarly, companies have shown interest in developing specialized career / job sites where they advertise their own job openings. Technology has enabled company career sites to become a very effective tool in attracting and maintain candidates' interest, supporting extensively the employer branding initiatives and policies a company may undertake (Lievens \& Slaughter, 2016). For example, companies can include in their career sites video-testimonials of current employees describing what it means to work for this company, or recruiters explaining the hiring process to interested candidates. In addition, companies may undertake supplementary steps, such as measuring site visits, improving website characteristics, tracking and following applicants across different media, such as on social media, etc. Sooner rather than later we will see job ads common in digital marketing but still new in human resources, such as SEO (search engine specialization) hiring co-ordinator and SEO career analyst.

Social media though and social networking websites have been the most important development in the field of digital attraction. A topic that has attracted extensive interest from practitioners worldwide but still remains an area which tries to catch up practice and has only recently received increased research interest. In one of the first studies on this topic we explored how job seekers and recruiters use Social Networking Websites (Nikolaou, 2014), arguing that social media offer the opportunity to candidates for increased networking in a cheap and effective way, but also how useful they can be for recruiters as a means of attracting passive candidates, i.e., people who are not actively looking for a job, but who might pay attention to an interesting offer or suggestion by a recruiter. Nevertheless, recent studies have challenged the wide acceptance of social media, raising major concerns about their usefulness both among recruiters (Zhang et al., 2020) and job-seekers (Johnson \& Leo, 2020). More research is urgently needed in this field, since there is no sign that the use of LinkedIn especially is going to go away any time soon. On the contrary, early signs have shown that the advent of COVID-19 has shifted both job seekers and recruiters towards more extensive use of social media, according to recent reports in the media (e.g., Wilding, 2020).

\section{Technology in Screening}

The second stage of the process includes screening candidates' available information regarding their suitability for the position. Traditionally, highly specialized companies were involved in difficult to handle and execute background screening, especially for sensitive positions, such as in the army, the security forces and in financial institutions. The emergence of social media has transformed the scene there as well. Cybervetting has been defined as the use of nongovernmental, noninstitutional online tools or sites (e.g., search engines and social network sites) from employers in order to extract informal, often personal information about prospective or current 
employees (Berkelaar \& Buzzanell, 2014). Cook et al. (2020) have recently published an article describing the development of a new scale measuring cybervetting in an attempt to support researchers doing research in this topic. Cybervetting seems to have a strong negative impact on applicant reactions, an important topic we will discuss later. Candidates expect that professionallyoriented websites, such as LinkedIn, will be accessed by potential employers and often encourage this access by including their LinkedIn profile link in their CVs or application forms, but they do not have the same attitude towards personally-oriented social media, such as Facebook or Instagram (Nikolaou et al., 2020).

Technological developments have also facilitated the administration and execution of many time-consuming tasks in the screening process. For example, the extensive use of applicant tracking systems (ATS) can reduce the duration of the screening process, providing effective resume storage, resume parsing and keyword search for very large numbers of applications. They can also offer additional opportunities of combining the information candidates provide themselves with the information publicly available for them on social media. Many HR start-up companies have focused on these issues recently, since they seem to provide increased opportunities for collaboration with computer/data scientists and the application of technologies, such as data mining, machine translation or even artificial intelligence.

\section{Technology in Selection}

Traditionally, work and organizational psychologists studying the impact of technology in employee selection have focused on on-line testing (Ryan \& Ployhart, 2014). More recently though two new selection methods have attracted increased attention. These are the asynchronous interviewing and gamification/games-based assessment, especially in relation to applicant reactions and candidate experience.

The asynchronous interview, often also called video or digital interview, is defined as the type of interview where candidates are required to record their responses to a set of interview questions they are given and submit them on-line. The digital interview is more likely to be used during the initial steps of the selection process in order to assess minimum job requirements and reduce the applicants' pool. Managers might interview several applicants at the same time without being present, while multiple raters might view the interview afterwards in order to collectively reach to an agreement (Brenner et al., 2016). Companies specializing in data analytics in selection attempt to measure many indicators of the applicant during the digital interviews, such as the number of times they blinked, seconds between responses, body temperature changes, word speed, and so on (e.g., HireVue); sometimes with the use of sensor devices, automatic extraction and evaluation of data and visualization to automate the entire interview process (Langer et al., 2019). On the other hand, candidates have the opportunity to apply to international job positions, thus saving money and time (Guchait et al., 2014). However, the first studies exploring how participants perceive the digital interview and also how effective it is compared to the traditional interview were not very supportive. Langer et al. (2017) showed no difference in organizational attractiveness levels, participants considered digital interviews to be creepier and less personal, reporting increased privacy concerns.

Another major development in employee selection methods has been gamification and games-based assessment (GBA). Gamification refers to the incorporation of game elements in non-gaming contexts, such as employee recruitment and selection (Georgiou et al., 2019). Gamifying a selection method often implies the conversion and adoption of an existing selection method, such as a personality test or a situational judgment test into a gamifying version. Using mobile or computing devices, candidates are exposed to a gamified environment or virtual word with questions that candidates have to answer. The use of game elements in the selection process might promote fun, transparency, challenge and interaction. On the other hand, in GBA and serious games, actual on-line or traditional games are used, sometimes specifically built for use in selection, albeit not necessarily. Gamification and GBA have recently attracted a lot of attention especially among practitioners, since they seem to offer a number of advantages compared to traditional selection methods. For example, they seem to appeal to younger candidates, not necessarily with past gaming experience. Early research in this field has shown that gamification can be a reliable and valid selection method (Georgiou et al., 2019; Nikolaou et al., 2019) raising positive reactions among candidates and increased organizational attractiveness (Georgiou \& Nikolaou, 2020; Gkorezis et al., 2020). However, as it is the case for any new selection method, we need more research to confirm further its usefulness and applicability both from a theoretical and a practical viewpoint.

Applicant reactions research has become an important topic of study within the broader area of employee selection and assessment. It has been a fruitful and highly productive stream of research since the mid-1980s. McCarthy et al. (2017) describe applicant reactions, as "...how job candidates perceive and respond to selection tools (e.g., personality tests, work samples, situational judgment tests) on the basis of their application experience. They include perceptions of fairness and justice, feelings of anxiety, and levels of motivation, among others" 
(p. 1695). It is obvious that applicant reactions, often called in practice "candidate experience" is an important area where technology has a major impact. For example, the lack of a personal, face-to-face interaction with the interviewer, and the candidates' perception of inability to influence the outcome of the interview process, as in the traditional interview (Nikolaou, 2011; Nikolaou \& Judge, 2007), has been a major drawback of the digital interview and it will be difficult to change this in the future, despite the obvious advantages they offer. Moreover, candidates nowadays have increased opportunities to share their experiences with other candidates. The selection process is not any more an isolated and "behind the closed doors" process, as it used to be in the past. More than 41 million people per month now use Glassdoor, a website providing for free "company reviews, CEO approval ratings, salary reports, interview reviews and questions, office photos and more"1. Applicants sharing their negative experiences with an employer in social media and other websites, such as glassdoor.com, are quite likely to generate a negative word of mouth and create a respective image of potential employers, negatively affecting the company's employer branding, or even its financial valuation. Thus, this information might affect candidates' job search activities and/or create negative word of mouth between potential job seekers, even without immediate experience of the organization's recruitment and selection process.

\section{Technology E On-Boarding}

The final stage of the selection cycle includes the dayafter the candidate joins an organization, as a newcomer. The importance of on-boarding and socialization have been widely explored as a significant factor of employee adjustment (Bauer et al., 2007; Bauer et al., in press). The use of socialization techniques, such as formal or informal training, on-the-job training, coaching-mentoring, etc. have proven to be very effective for the quick adjustment of newcomers in their new roles. Many companies now make extensive use of technology in order to improve the usefulness of these techniques, offering access to specialized company apps, on-line training, e-mentoring for career development, intranet resembling social-media sites, such as Microsoft's Yammer, etc. (Sharma \& Bhatnagar, 2016). However, the potential of using technology in the whole cycle of the selection process, including on-boarding, will fulfil its purpose when companies will be able to make effective use of not only HR metrics but computer science methods as well, such as data mining with the combination of external (pre-entry) and internal (post-

\footnotetext{
${ }^{1}$ Glassdoor.com, 2017
}

entry) data bringing recruitment and selection in the big data era.

\section{Proposals for Future Research}

It is obvious that technology has had a major impact across the whole recruitment and selection cycle. Unfortunately, research has not followed in the same pace, and only recently we see published empirical studies on these topics. For example, there is still limited research on how company career sites, job boards and social media really make an impact on attracting and screening suitable candidates. A handful of studies have recently focused on cybervetting and the impact of information elicited from this strategy on the validity and fairness of the selection process. Finally, two new selection methods (digital interview and gamification), which have attracted increased attention from practitioners and, as a result of the recent pandemic they will be used extensively in the future (especially the former), still lack important validation studies. Furthermore, in our paper published recently (Woods et al., 2020), we discuss and propose a future research agenda with a special focus on digital selection procedures (DSPs). We focus our proposals into six core areas; (a) the construct validity of DSPs; (b) creating a literature on validity that promotes improvement and development of DSPs; (c) exploring the criterion-related validities of DSPs; (d) understanding adverse impact and bias; (e) development of current and up-to-date perspectives on applicant reactions in relation to DSPs, and finally ( $f$ ) understanding the impact of privacy concerns for applicants and their potential implications for organizations.

The impact of technology on recruitment and selection is a fascinating area of research and practice both for work and organizational psychologists, offering also increased opportunities for collaboration with other disciplines, such as computer/data science, informatics, etc. and it is an opportunity not to be missed for our field.

\section{References}

Bartram, D. (2000). Internet recruitment and selection: Kissing frogs to find princes. International Journal of Selection and Assessment, 8(4), 261-274. https: / / doi.org/10.1111/14682389.00155

Bauer, T. N., Bodner, T., Erdogan, B., Truxillo, D. M., \& Tucker, J. S. (2007). Newcomer adjustment during organizational socialization: A meta-analytic review of antecedents, outcomes, and methods. Journal of Applied Psychology, 92(3), 707-721. https:/ / doi.org/10.1037/00219010.92.3.707

Bauer, T. N., Erdogan, B., Caughlin, D., Ellis, A. M., \& Kurkoski, J. (in press). Jump-starting the socialization experience: The longitudinal role of Day 1 newcomer 
resources on adjustment. Journal of Management. https: / / doi.org/10.1177/0149206320962835

Berkelaar, B. L., \& Buzzanell, P. M. (2014). Cybervetting, person-environment fit, and personnel selection: Employers' surveillance and sensemaking of job applicants' online information. Journal of Applied Communication Research, 42(4), 456-476. https: / / doi.org/10.1080/00909882.2014.954595

Brenner, F. S., Ortner, T. M., \& Fay, D. (2016). Asynchronous video interviewing as a new technology in personnel selection: The applicant's point of view. Frontiers in Psychology, 7, Article 863. https: / / doi.org/10.3389/ fpsyg.2016.00863

Chapman, D. S., \& Mayers, D. (2015). Recruitment processes and organizational attraction. In I. Nikolaou \& J. K. Oostrom (Eds.), Employee recruitment, selection and assessment. Contemporary issues for theory and practice (pp. 27-42). Routledge/Psychology Press.

Cook, R., Jones-Chick, R., Roulin, N., \& O'Rourke, K. (2020). Job seekers' attitudes toward cybervetting: Scale development, validation, and platform comparison. International Journal of Selection and Assessment, 28, 383-398. https:/ / doi.org/10.1111/ijsa.12300

Georgiou, K., Gouras, A., \& Nikolaou, I. (2019). Gamification in employee selection: The development of a gamified assessment. International Journal of Selection and Assessment, 27(2), 91-103. https:/ / doi.org/10.1111/ijsa.12240

Georgiou, K., \& Nikolaou, I. (2020). Are applicants in favor of traditional or gamified assessment methods? Exploring applicant reactions towards a gamified selection method. Computers in Human Behavior, 109, Article 106356. https: / / doi.org/10.1016/j.chb.2020.106356

Gkorezis, P., Georgiou, K., Nikolaou, I., \& Kyriazati, A. (2020). Gamified or traditional situational judgement test? A moderated mediation model of recommendation intentions via organizational attractiveness. European Journal of Work and Organizational Psychology. https: / / doi.org/10.1080/ 1359432X.2020.1746827

Guchait, P., Ruetzler, T., Taylor, J., \& Toldi, N. (2014). Video interviewing: A potential selection tool for hospitality managers-A study to understand applicant perspective. International Journal of Hospitality Management, 36, 90-100. http:/ / doi.org/10.1016/j.ijhm.2013.08.004

Johnson, M. A., \& Leo, C. (2020). The inefficacy of LinkedIn? A latent change model and experimental test of using LinkedIn for job search. Journal of Applied Psychology, 105(11), 1262-1280. https:/ / doi.org/10.1037/ap10000491

Karakanian, M. (2000). Are human resources departments ready for E-HR? Information Systems Management, 17(4), 31-35. https: / / doi.org/10.1201/1078/

43193.17.4.20000901/31250.6

Langer, M., König, C. J., \& Krause, K. (2017). Examining digital interviews for personnel selection: Applicant reactions and interviewer ratings. International Journal of Selection and Assessment, 25(4), 371-382. https: / / doi.org/doi: 10.1111/ijsa.12191

Langer, M., König, C. J., \& Papathanasiou, M. (2019). Highly automated job interviews: Acceptance under the influence of stakes. International Journal of Selection and Assessment, 27(3), 217-234. https://doi.org/10.1111/ijsa.12246
Lievens, F., \& Harris, M. M. (2003). Research on Internet recruiting and testing: Current status and future directions. In C. L. Cooper \& I. T. Robertson (Eds.), International Review of Industrial and Organizational Psychology 2003 (Vol. 18, pp. 131-165). Wiley. https://doi.org/10.1002/ 0470013346.ch4

Lievens, F., \& Slaughter, J. E. (2016). Employer image and employer branding: What we know and what we need to know. Annual Review of Organizational Psychology and Organizational Behavior, 3, 407-440. http:/ / doi.org/10.1146/ annurev-orgpsych-041015-062501

Markoulli, M. P., Lee, C. I. S. G., Byington, E., \& Felps, W. A. (2017). Mapping human resource management: Reviewing the field and charting future directions. Human Resource Management Review, 27(3), 367-396. https:/ / doi.org/ 10.1016/j.hrmr.2016.10.001

McCarthy, J. M., Bauer, T. N., Truxillo, D. M., Anderson, N. R., Costa, A. C., \& Ahmed, S. M. (2017). Applicant perspectives during selection: A review addressing "So What?,"What's New?," and "Where to Next?". Journal of Management, 43(6), 1693-1725.

Montuschi, P., Gatteschi, V., Lamberti, F., Sanna, A., \& Demartini, C. (2014). Job recruitment and job seeking processes: How technology can help. IT Professional, 16(5), 41-49. https: / / doi.org/10.1109/MITP.2013.62

Nikolaou, I. (2011). Core processes and applicant reactions to the employment interview: An exploratory study in Greece. The International Journal of Human Resource Management, 22 (10), 2185-2201. https:/ / doi.org/10.1080/ 09585192.2011.580187

Nikolaou, I. (2014). Social networking web sites in job search and employee recruitment. International Journal of Selection and Assessment, 22(2), 179-189. https:/ / doi.org/10.1111/ ijsa.12067

Nikolaou, I., Ahmed, S., Woods, S. A., Anderson, N., \& Costa, A. C. (2020). Applicant reactions towards Internet-based selection methods [Manuscript in preparation] Department of Management Science \& Technology, Athens University of Economics \& Business.

Nikolaou, I., Georgiou, K., \& Kotsasarlidou, V. (2019). Exploring the relationship of a gamified assessment with performance. The Spanish Journal of Psychology, 22, Article E6. https://doi.org/10.1017/sjp.2019.5

Nikolaou, I., \& Judge, T. A. (2007). Fairness reactions to personnel selection techniques in Greece: The role of core self-evaluations. International Journal of Selection and Assessment, 15(2), 206-219. https:/ / doi.org/10.1111/j.14682389.2007.00382.x

Obaid, I., Farooq, M. S., \& Abid, A. (2020). Gamification for recruitment and job training: model,taxonomy, and challenges. IEEE Access, 8, 65164-65178. https: / / doi.org/ 10.1109/ACCESS.2020.2984178

Ryan, A. M., \& Ployhart, R. E. (2014). A century of selection. Annual Review of Psychology, 65(1), 693-717. https: / / doi.org/ 10.1146/annurev-psych-010213-115134

Sharma, A., \& Bhatnagar, J. (2016). Enterprise social media at work: Web-based solutions for employee engagement. Human Resource Management International Digest, 24, 16-19. http:/ / doi.org/10.1108/HRMID-04-2016-0055 
Stanton, J. M., \& Coovert, M. D. (2004). Turbulent waters: The intersection of information technology and human resources [Guest editors' note]. Human Resource Management, 43(2-3), 121-125. https:/ / doi.org/10.1002/hrm.20010

Taylor, M. S., \& Collins, C. J. (2000). Organizational recruitment: Enhancing the intersection of research and practice. In C. Cooper \& E. Locke (Eds.), Industrial and Organizational Psychology: Linking Theory with Practice. Citeseer. https:// digitalcommons.ilr.cornell.edu/articles/568/

van Iddekinge, C. H., Lanivich, S. E., Roth, P. L., \& Junco, E. (2016). Social media for selection? Validity and adverse impact potential of a Facebook-based assessment. Journal of Management, 42(7), 1811-1835. https: / / doi.org/10.1177/ 0149206313515524

Wilding, M. (2020, April 27). How to job search in the age of COVID-19, according to a career coach. Forbes. https://www.forbes.com/sites/melodywilding/2020/04/ 27/how-to-job-search-in-the-age-of-covid-19-according-toa-career-coach $/$ ?sh=6a2a02235e33

Woods, S. A., Ahmed, S., Nikolaou, I., Costa, A. C., \& Anderson, N. R. (2020). Personnel selection in the digital age: A review of validity and applicant reactions, and future research challenges. European Journal of Work and Organizational Psychology, 29(1), 64-77. https: / / doi.org/10.1080/ 1359432X.2019.1681401

Zhang, L., van Iddekinge, C. H., Arnold, J. D., Roth, P. L., Lievens, F., Lanivich, S. E., \& Jordan, S. L. (2020). What's on job seekers' social media sites? A content analysis and effects of structure on recruiter judgments and predictive validity. Journal of Applied Psychology, 105(12), 1530-1546. https: / / doi.org/10.1037/ap10000490 